\title{
Matlab Guidance Based Smart Gas Leakage Detection and Security System Using Analog to Digital Technique
}

\author{
Md. B. Hossain ${ }^{1}$, Saruar J. Shourov ${ }^{1}$, Md. M. Rana ${ }^{1.2}$ and Md. S. Anower ${ }^{1.2 .3}$ \\ ${ }^{1}$ Department of Electrical and Electronic Engineering, \\ ${ }^{1}$ Rajshahi University of Engineering and Technology, Rajshahi-6204, Bangladesh \\ ${ }^{2}$ Institute of Electrical and Electronic Engineers (IEEE), EEE Association of \\ RUET \\ biplobh.eee10@gmail.com,shourov101062@gmail.com, \\ masud_0119e@yahoo.com andmd.shamimanower@yahoo.com ${ }^{1.2}$
}

\begin{abstract}
The work describing in this paper develops and demonstrates an analog to digital conversion $(A D C)$ technique based an electronic device which is used to detect gas leakage using mechanical sensors at households, industries, vehicles, gas stations etc. where detection of gas leakage is an important issue to avoid any uncertainty. The device consists of a processing section which takes input, processes it and provides output. Corresponding to this output, it starts exhaust fan and light emitting diode (LED) is on, if concentration of gas exceeds a certain level, starts buzzer (alarm), switch off the gas power supply and notifies the consumer by sending an alert message through the monitoring computer. The gas concentration level for a particular operational area will be stored in Matlab "Database Explorer Tool" in order to get an overview of gas status of this area for future analysis such as probability to take accident and so on.
\end{abstract}

Keywords: Analog to digital conversion (ADC), bus serial port, compressed natural gas $(C N G)$, liquid crystal display $(L C D)$, liquid petroleum gas $(L P G)$, parts per million $(P P M)$

\section{Introduction}

In common usage, a gas leak refers to a leak of natural gas, from a pipe or other containment, into a living area or any other area where the gas should not be [1]. LPG consists of mixture of propane and butane which is highly flammable chemical. It is odorless gas due to which Ethanethoil is added as powerful odorant, so that leakage can be easily detected. LPG is one of the alternate fuels used now a day [1,2]. CNG is widely used in transportation. Natural gas used in household for cooking or heating, mostly consists of Methane. As the use of gases is increasing day by day, so the risk of leakage causing accidents is also playing significantly. A number of fire accidents which are debted for human death and injury due to the explosion of LPG have been happened in recent years [3]. The main causes of gas leakage accidents are mentioned in [6], these are: external interference, corrosion, construction defects, material failure and ground movement. To reduce this accident there should have a requirement for a solution to detect and also prevent leakage of LPG. For example by means of constant monitoring sensor reference nodes are placed in pipeline connecting points and pipeline passage and its ending junctions so it is easy to locate the leakage surface and hence the chance of occurring accidents can be minimized [15].

Due to the lack of using proper leakage detection system, a number of dangerous accidents occurred during the last few decades, which took a lot of man power as well as huge economic losses. For example, in [4], the accident that was considered the world's 
worst industrial disaster occurred due to explosion of LPG in Malaysia. The case was reported in Johor Bahru, Malaysia where a young couple for reason of the inhalation of Carbon Monoxide (CO). This case took loss after lethal doses of the gas speeded into the car's inner chamber by means of its extractor exhaust system, which was observed to have been modified. An examination of the bodies showed that there is no sign of trauma [5]. This study is a very little fractional overview of accidents occurred due to gas leakage. In the whole world, these types of unexpected human injurious, financial losses are occurring continuously due to the lack of proper leakage detection and protection system.

\section{Previous Work}

Previous days, a number of jobs related with gas leakage detection and ensure security system, have been implemented, among these some were theoretical research approach and some were demonstrated in practical field to detect the leakage but both approaches were effective. A work was done by Brodetsky and Savic, [7] which monitored leakage continuously, but not surveyed for further analysis. Gopalsami and Raptis [8] reported Gases such as methane are not weightier than air and this variation in density can be produced a specific radar effective signature that can be evaluated in order to detect the potentiality of leakage. This method is an effective one but also highly expensive. Another leakage detection system was proposed by Kroll, et al., in 2009 [9]. This method can be used from ground and aerial vehicles, and was also successfully installed on autonomous robots but however expensive. Sandberg, et al., [10] in 1989 used a sensing cable sensitive to hydro-carbons in a project that capable to detect leaks with an accuracy of about 20 meters. This project is appreciable for decade of nineteenth but unavailability of sensing cable, make it unpopular.

On the field of gas leak detection and provide safety against intrusion, previously a number of reviews-shaped were done either as an element of research papers/journal reports on a certain leak monitoring and detection section or practical overview of other gas related subjects. These previous work are Lewicki 2010 [11], Lawrence 2009 [12], Furness 2009 [13], Batzias 2011 [14]. In [16] there also one limitation of this method is that it cannot individually specify the specific reason of observable gas stress. Although they report an invaluable overview on existent leak detection arms.

This paper discusses the detection of gas leakage, practical application to the daily life at different applicable sectors and ensures the security of human being, economics, environment etc. from the accidents caused by leakage. While using at household, industries, vehicles etc. this device detects the leakage that is concentration of gas is higher than first critical level, it starts exhaust fan. It also sends notification to the customer's computer using serial communication. If the concentration level of gas exceeds the second critical level, that indicates emergency condition, then the device will shut down the gas supply, starts LED and buzzer and continuously sends alert notification to the consumer periodically until the concentration level reduces to normal.

\section{Proposed Model}

This paper introduces a model of Gas leakage detection and security system that ensures the security from human injuries, financial losses and environmental hazards. It mainly stands for ensuring the gas leakage detection at residential and commercial area such as house-holds, where gases are used for cooking, power plants to generate power, factories and industries as raw materials. So the accidents due to gas leakage such as explosion, fire risk, contamination of air etc. can be dramatically reduced. This device includes a gas sensing unit that senses the concentration of gases in the operational sector, a display unit shows the concentration level of gases, an alarm circuitry alerts the 
people around the area and a reduction unit reduces the concentration level of the area. All data of the above operations will transmitted to the controller computer where the operator can observe the present condition of the concentration level and can take necessary action (ex. Call fire service center or others action). The level of gas intensity is stored in the central computer to observe and analysis those in future which are explained in details at the simulation. One can easily make a monthly or yearly complete documentary from these data.

\section{Methodology}

In the proposal work, mainly 3 methods are used, first one is 10 bit "Analog to Digital conversion (A/D)", second one is "Universal Synchronous Asynchronous Receiver and Transmitter (USART)", and the last one is "Two Wire Communication (TWI)". The function of A/D is to convert inputed mechanical signal such as Gas concentration in this model and provides output as a numeric value (digital signal) with respect to the corresponding gas concentration. The function of USART is the data communication between two peripherals. The Two-wire Serial Interface (TWI) is ideally preferred for commercial microcontroller applications. The TWI protocol accepts the system designer to interconnect up to 128 different devices using only two bi-directional bus lines, one for clock (SCL) and other for data (SDA). The only external hardware is needed to implement the bus is a single pull-up resistor for each of the TWI bus lines. All devices are interlinked to each other having individual self-addresses, and mechanisms for resolving bus contention are inherent in the TWI protocol [17].

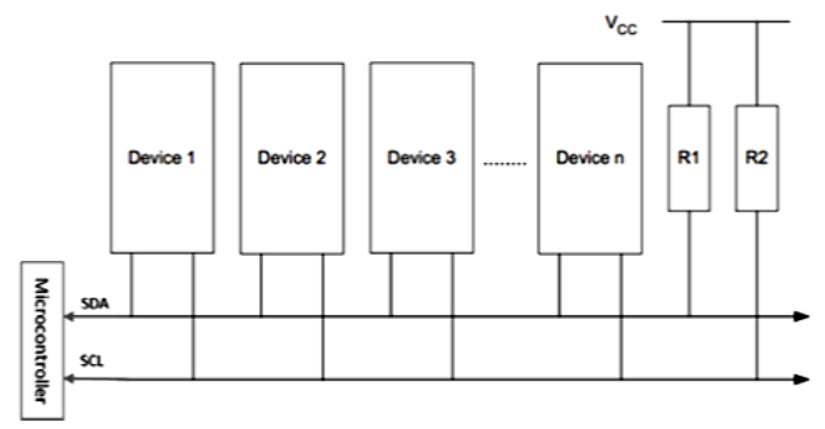

Figure 1. TWI Bus Interconnection

Device $1,2,3 \ldots . \mathrm{n}$ are called slave and master device is microcontroller, which only has the might to address the slave device.

\section{System Components and Working Procedure}

The proposed project consists of a microcontroller acts as simply processing unit, a DC power supply unit which activates the device, an input unit through which processing unit reads analog input and a set of output units including a LCD, sound circuitry, relay driven circuit, light alarm and a USART communication unit. The overall system operation block diagram is visualized in Figure 2. 


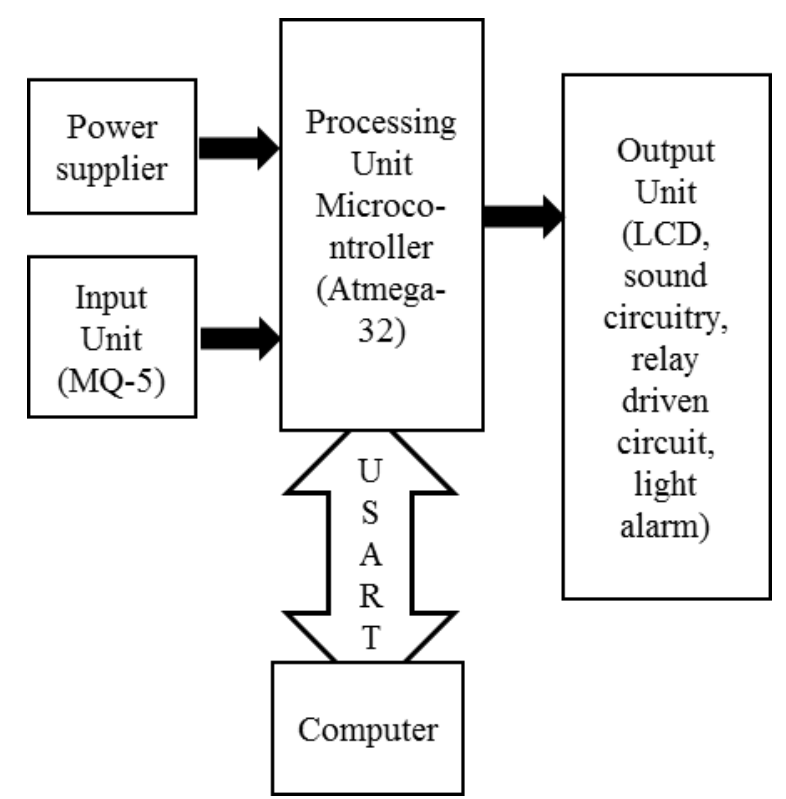

Figure 2. Block Diagram of Gas Leakage Detection and Security System

The device is ready to read gas concentration level from the environment through the Gas Sensor Module when the power supply circuit is ON. After that microcontroller reads analog environmental data through the MQ-5 gas sensor module, processes it and provides output to the LCD monitor and controller computer. If the concentration level exceeds the first critical level then the microcontroller starts Exhaust Fan, LED "ON", Monitoring data and sends data to computer as well as LCD. Using exhaust fan the device will try to minimize the concentration level of the gas in the operational area. Yet, the level of gas concentration still increasing and exceeds the second critical level, then it will Power OFF the Gas Supply, starts alarm, monitoring data and sends data to computer. The first critical level and the second critical level is user defined. Users can change the critical level simply replacing by new one using Matlab by simply inputting the critical value without any hardware modification of the device. The observed data taken from Matlab is stored into the "Test \& Measurement Tool" window of Matlab and one can easily analyses the previous level of gas concentration of that area using the surveying statistics.

\section{Model Simulation and Observation}

The analytical device operation was simulated using Proteus 7 professional software. The simulated circuit diagram is given below Figure where each unit is presented as a prototype of their operation for simulation purpose. Figure 3 is the representation of the ON mode device when the gas intensity level is $505 \mathrm{ppm}$. This intensity level is considered as the normal state for simulation purpose. The time domain response across the gas sensor is steady state in this condition. 


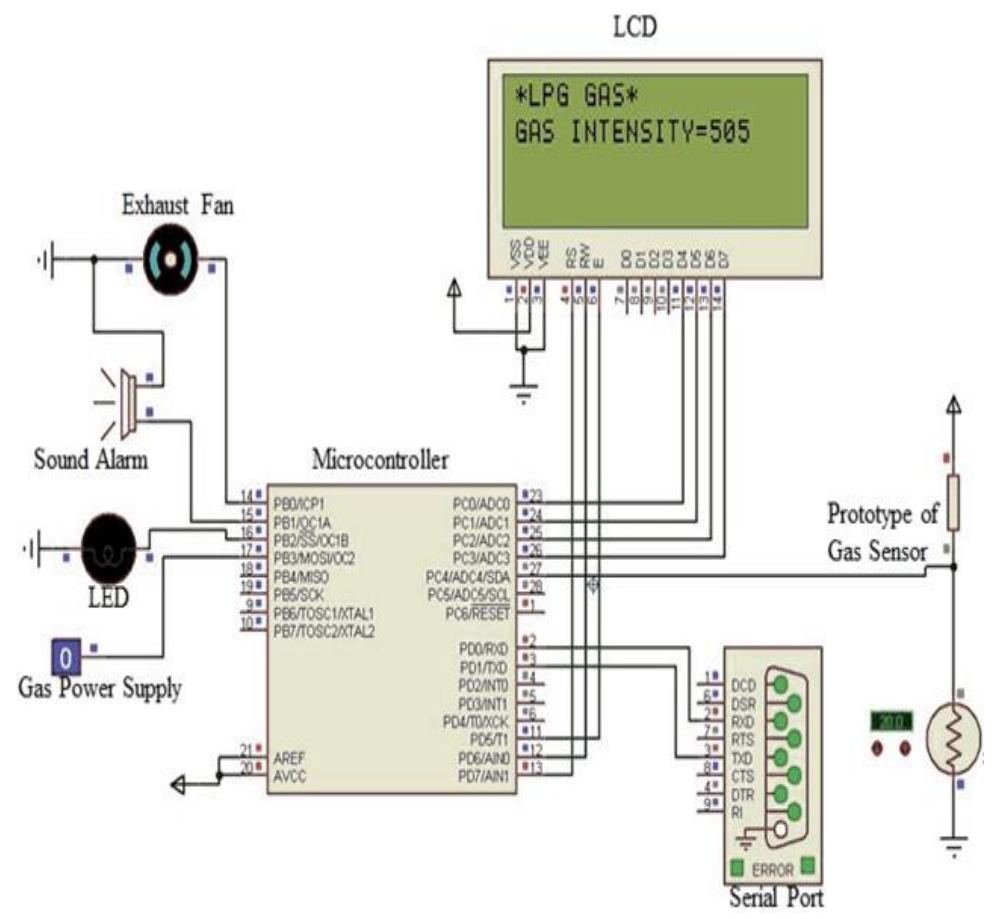

Figure 3. Circuit Diagram

The microcontroller that is fed from a sensor receives an input response that can be shown in Figure 4a where the input is steady state but gives a variation when a slight change of gas concentration. The input signal can be graphically observed by oscilloscope. From the simulation observation, it was noticed that if any transient condition at input from steady state, then simulated output was fluctuated 1 to 3 volts. Figure 4.b shows the simulated output in simulink Matlab window at Scope. Figure 4c shows the statistics of the surveying report of the previous data that are stored in the computer memory. Consumer can easily collect the information of leakage of immediate past from this statistics.

Microcontroller reads ADC data from MQ-5 sensor continuously and responses on the basis of ADC data. If the concentration level exceeds the first critical level by gradually increase of gas intensity, then the sensor sense the input signal similar to Figure 5a which is taken from oscilloscope, and microcontroller reads it and sends logical high signal to exhaust fan and LED shown in Figure $5 \mathrm{~d}$ is the simulated output corresponding to this input and Figure $5 \mathrm{c}$ is the result shown at LCD display. 


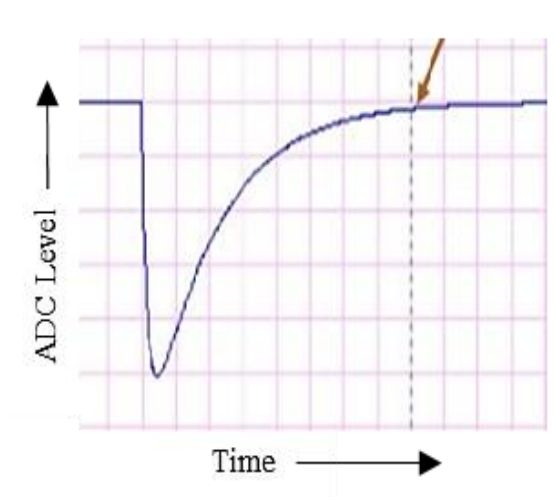

a. input observation

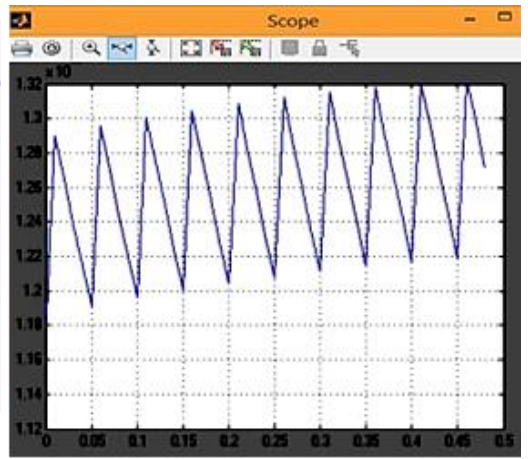

b. output observation

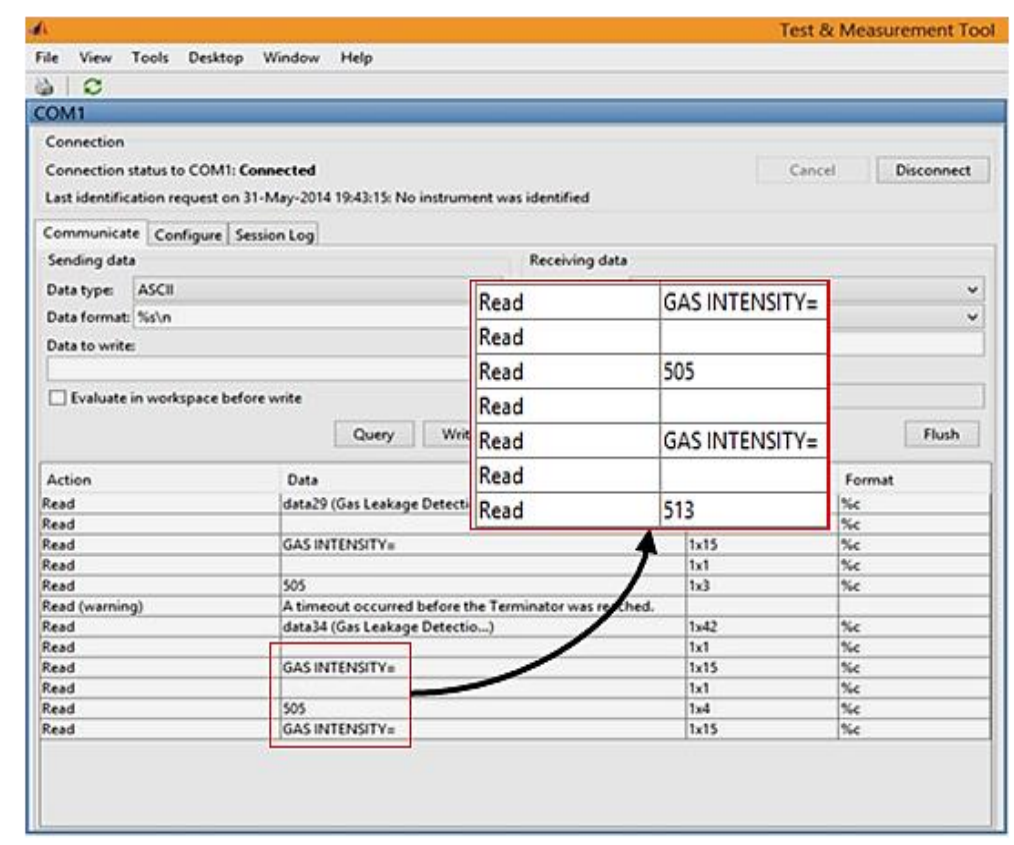

c. statistics of the stored data in Matlab

Figure 4. Input, Output and Data Statistics Analysis at Normal State

From Figure 5d the red indicator indicates the high state that is the exhaust fan and the LED are ON, the buzzer is OFF and the pin 17 of microcontroller controls the gas power supply unit. It is switched OFF at this state that is confirmed by the red pointer or 1 in the prototype. Figure 5c and Figure 5e are the result in LCD and in the display of monitoring computer at Terminal-2 virtual serial connector software respectively for first critical level where the gas intensity is $750 \mathrm{ppm}$. Similar as normal state the data is stored in the computer for first critical level shown in Figure5f.

The exhaust fan will try to discharge the exceed gases from the operational site. The LED will show the identification of exceeded concentration level and the LCD and computer will show the intensity level. But if the exhaust fan fails to keep the concentration level below the desired value and gas intensity is above the second critical level then microcontroller receives data from sensor which can be represented in Figure 6a that is also observed by oscilloscope. 


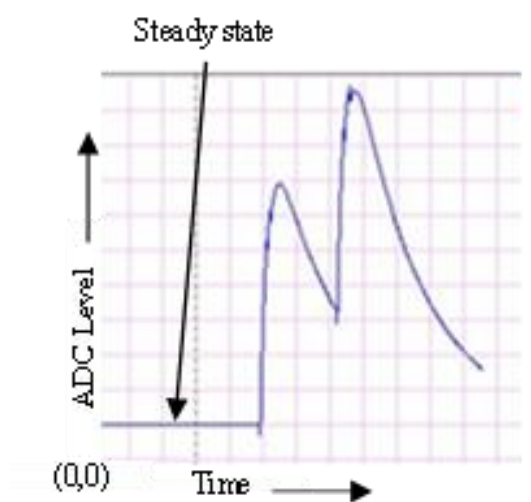

a. Irqut doservation at 1st critical level

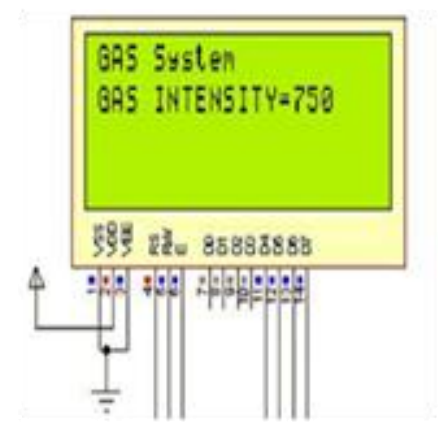

c. Output observation at LCD

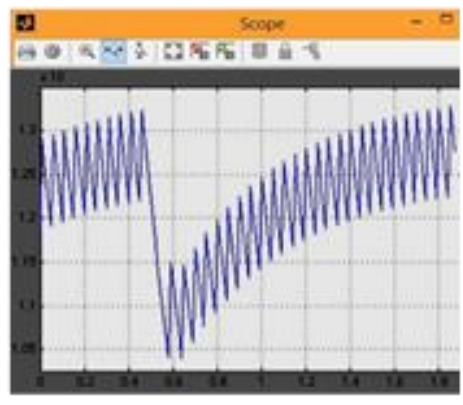

b. Outputobservation at 1st critical level

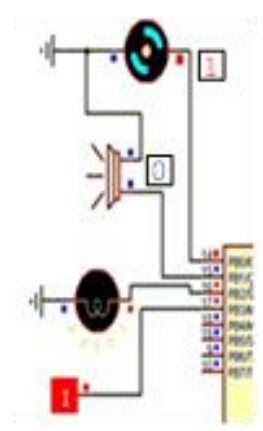

d Logical change of Device

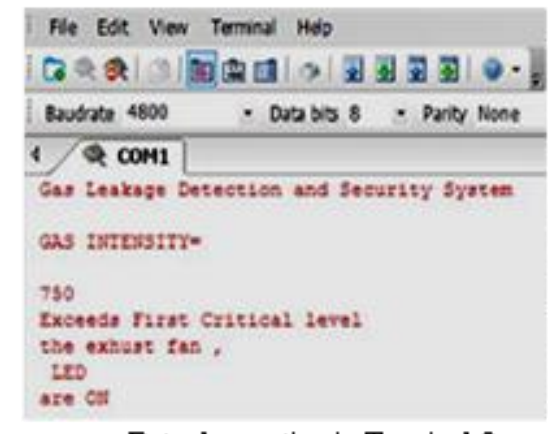

e. Data doservation in Terminal-2

\begin{tabular}{|c|c|}
\hline Read & GASINTENSTY: \\
\hline \multicolumn{2}{|l|}{ Pead } \\
\hline Pead & 750 \\
\hline Read & data 30 ; the enust fan $\alpha$ Ala. \\
\hline \multicolumn{2}{|l|}{ Pead } \\
\hline \multicolumn{2}{|l|}{ Read } \\
\hline Read & GASINTENSTY: \\
\hline \multicolumn{2}{|l|}{ Read } \\
\hline Pead & 787 \\
\hline
\end{tabular}

f. Data observation in Matlab

\section{Figure 5. Input, Output and Data Statistics Analysis at 1st Critical State}

This increasing input response makes the continuous ON mode of exhaust fan, LED and starts the buzzer to warn the people at the site and also switch OFF the gas power supply by sending low response from microcontroller. Figure $6 \mathrm{~b}$ and Figure $6 \mathrm{e}$ shows the output at LCD and observation at terminal-2 for second critical state. The data shown in LCD and in the display of monitoring computer for second critical level where the gas intensity is $1013 \mathrm{ppm}$. Just like as before, the observation data is stored into the computer which is shown in Figure 6f. The simulated output is in Figure 6c. 


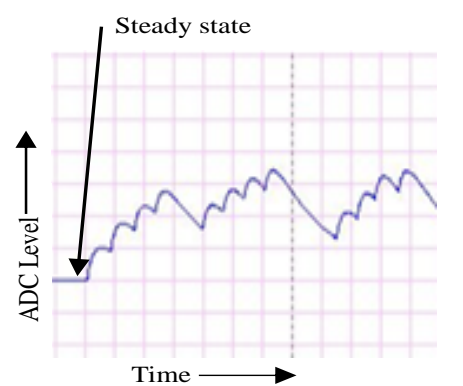

a. Input observation at 1 st critical level

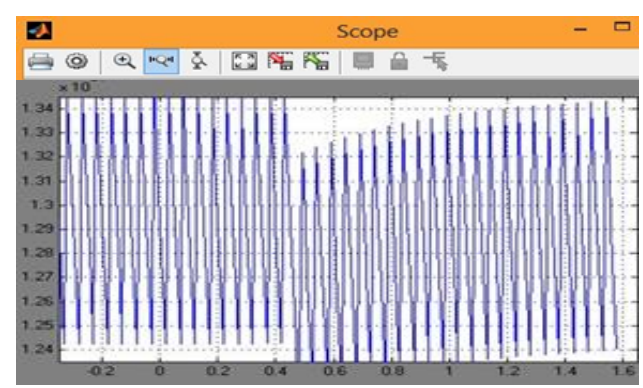

c. Output observation at 1 st critical level

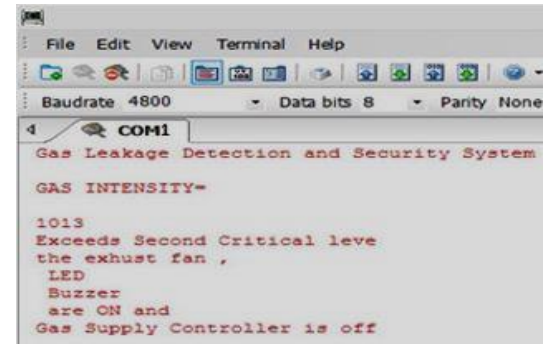

e. Data observation in Terminal-2

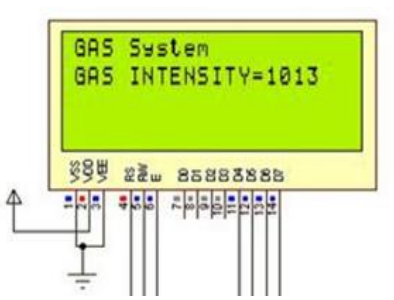

b. Output observation at LCD

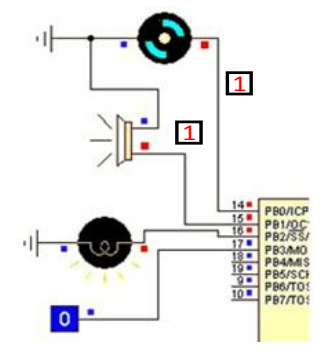

d. Logical change of Device

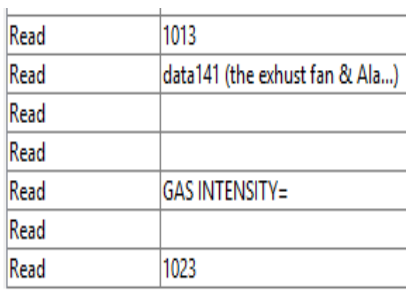

f. Data observation in Matlab

\section{Figure 6. Input, Output and Data Statistics Analysis at 2nd Critical State}

The data collected from the simulated output both for $1^{\text {st }}$ and $2^{\text {nd }}$ critical level, which may be observed in the following surveying graph which is plotted while simulation output is taken from the "Test \& Measurement Tool" window of Matlab.

The reference concentration level of gas is changeable according to the desireness of the operator of the controller computer by simply controlling the following feedback control system in Matlab Simulink window in Figure 8. Here, the Scope Sink, that is used before at every step of operation to display the Matlab simulation output graphically.

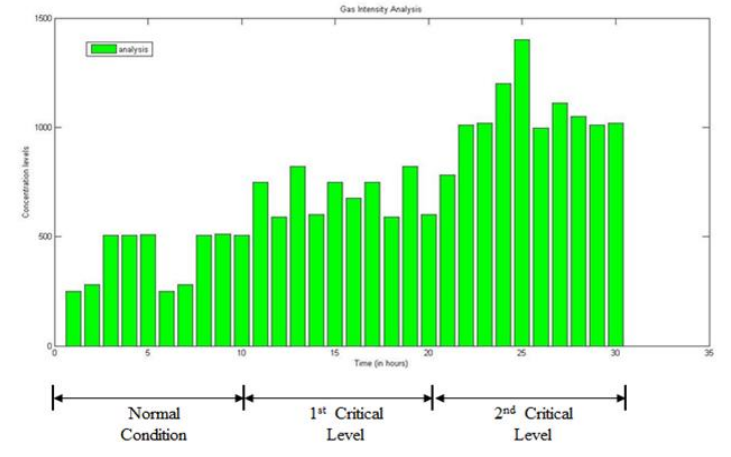

Figure 7. Survey Graph of Gas Intensity Level 


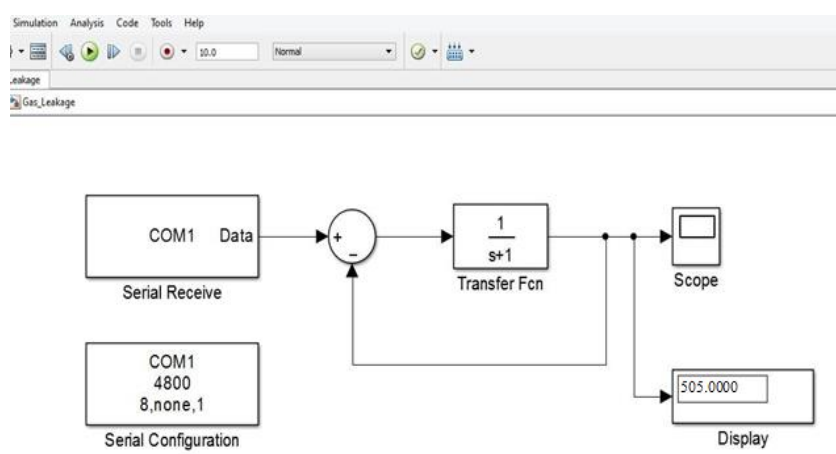

Figure 8. Feedback Control Simulink System

Users can also change the reference level of gas intensity by simply inputting the desired value at User Input Field shown in Figure 9. by Terminal-2 virtual serial connector software instead of using feedback control system.

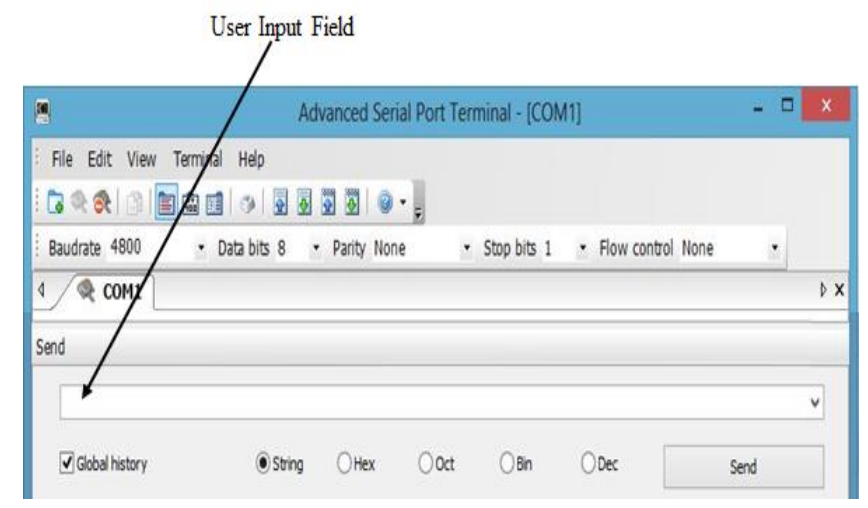

Figure 9. User Input Field

\section{Complete Experimental Setup}

The complete experimental setup and the output response at different critical level of proposed gas leakage detection and security system are given in Figure 10. Here, MQ-5 gas sensor senses the analog gas concentration level, converts it to digital signal and sends to the microcontroller. Then microcontroller analysis the data compares it to the reference level and provides output according to the command. The experimental hardware implementation shows the practical operation of the device. 


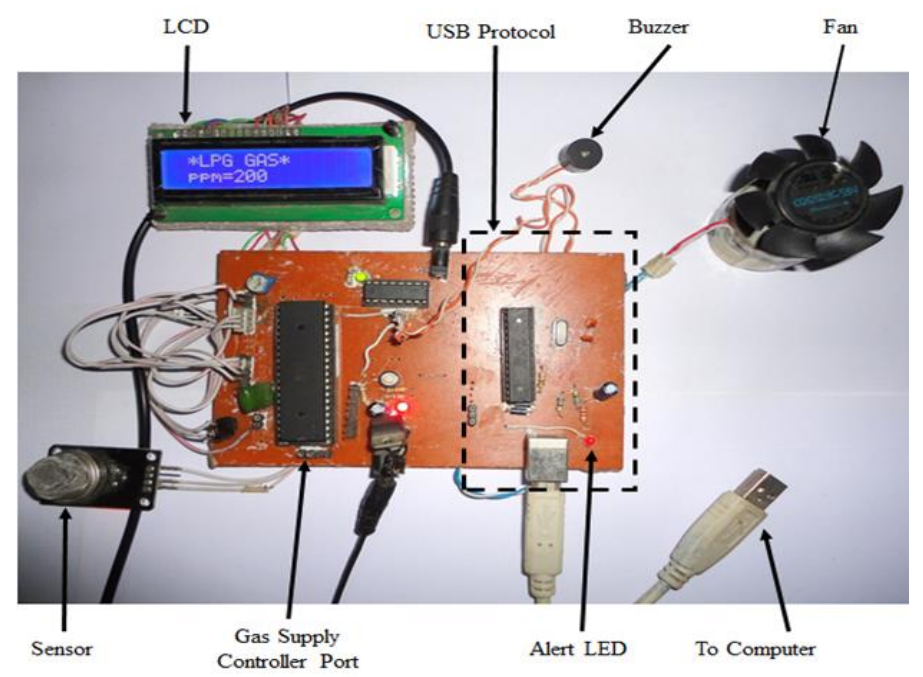

a. Complete Experimental Setup.

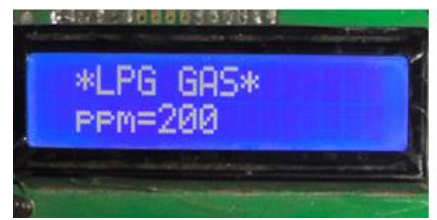

b. Result at LCD at normal state.

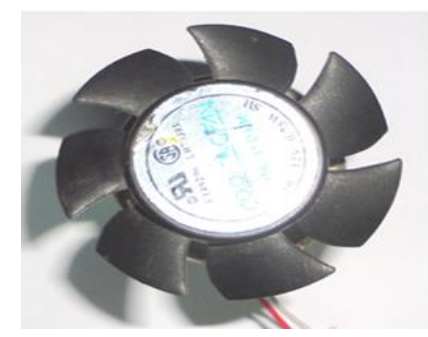

d. Exhaust fan OFF at normal state

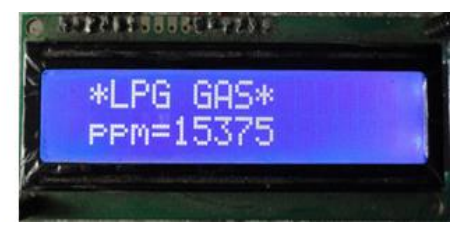

c. Result at LCD at $2^{\text {nd }}$ critical level.

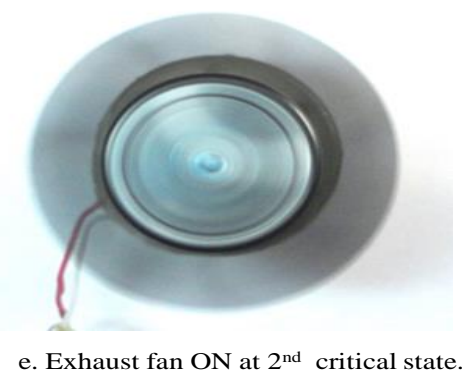

\section{Figure 10. Complete Device Setup and Result Observation}

\section{Conclusion}

The gas leakage detection and security system offers the maximum accurate operation. It ensures the detection of any types of gas leakage in a closed system and can take necessary action. It is a cost-effective system and the output rate is more desirable an accurate which is implemented as prototype using Matlab and practically examined. The next version of this device will be submitted soon with two basic developments. Firstly, it will be upgraded by using GPRS and sending data to the consumers through E-mail and sends continuous alert message to the nearest Fire Service Station if the concentration level exceeds the certain level. Secondly, at gas distribution system with high pressure, the gas leakage will also be detected by an optical fiber and the rate of change of the flow of gas at the distribution line.

\section{ACKNOWLEDGEMENT}

We would greatly thankful to Associate Prof. Dr. Md. Faruk Hossain for his guidance and patience throughout a long time of our project study. He has been kindfull with his time and has served many valuable advices that helped to bring up this work. We also 
want to thank him for his consultation that has been motivational to us, now and in our future career.

\section{References}

[1] A. Shrivastava, R. Prabhaker, R. Kumar and R. Verma, "GSM Based Gas Leakage Detection System", ITETEE, vol. 3, no. 2, (2013) May.

[2] W. Breuer, W. Becker, J. Deprez, E. Drope and H. Schmauch, "Electrochemical gas detector and method of using same", Patent 4141800, (2010) 27. http://www.freepatentsonline.com/4141800.html

[3] S. Rajitha and T. swapna, "A security alert system using gsm for gas leakage”, International Journal of VLSI and Embedded Systems (IJVES), vol. 3, no. 4, (2012) September-October, pp. 173-175.

[4] A. Che Soh, M. K. Hassan and A. J. Ishak, "Vehicle gas leakage detector", The Pacific Journal of Science and Technology, vol. 11, no. 2, (2010) November, pp. 66-76.

[5] "Couple died due to carbon monoxide gas", New Straits Times, (2008) August 1, http://www.nst.com.my/.

[6] "Gas pipeline incidents. tech. rep., european gas pipeline incident data group", 7th EGIG-report 19702007, (2008) December 1.

[7] I. Brodetsky and M. Savic, "Leak monitoring system for gas pipelines", in Proc. ICASSP-93, IEEE, vol. 3, (1993), pp. 17-20.

[8] N. Gopalsami and A. Raptis,"Millimeter-wave radar sensing of airborne chemicals. Microwave Theory and Techniques",IEEE Trans. Microwave Theory and Techniques., vol. 49, no. 4, (2001), pp. 646-653.

[9] A. Kroll, W. Baetz and D. Peretzki, "On autonomous detection of pressured air and gas leaks using passive IR-thermography for mobile robot application", in Proc. ICRA'09., IEEE , (2009), pp. 921-926.

[10] C. Sandberg, J. Holmes, K. McCoy and H. Koppitsch, "The application of a continuous leak detection system to pipelines and associated equipment”, IEEE Trans. Industry Applications, vol. 25, no. 5, (1989) Septmeber-October, pp. 906-909.

[11] J. L. Lewicki, G. E. Hilley, L. Dobeck and L. Spangler, "Dynamics of CO fluxes and concentrations during a shallow subsurface $\mathrm{CO}_{2}$ release", Environmental Earth Sciences, vol. 60, no. 2, (2010), pp. 285-297.

[12] C. J. Keith, K. S. Repasky, R. L. Lawrence, S. C. Jay and J. L. Carlsten,"Monito-ring effects of a controlled subsurface carbon dioxide release on vegetation using a hyperspectral imager",Int. J. Greenhouse Gas Control, vol. 3, (2009), pp. 626-632.

[13] "Pipeline leak detection techniques", E.W., M. (Ed.), Pipeline Rules of Thumb Handbook.Elsevier, NC, (2009), pp. 606-614.

[14] F. Batzias, C. Siontorou and P. M.Spanidis, "Designing a reliable leak bio-detection system for natural gas pipelines", International Journal of Hazardous Materials, vol. 186, no. 1, (2011) January, pp. 35-58.

[15] L. F. Diego, F. G. Labiano, P. Gayan, J. Cleaya, J. Palacios and J. Adanez, "Operation of a 10kWth chemical-looping combustor during 200h with a CuO-Al2O3 oxygen carrier”, Fuel, vol. 86, (2007), pp. 1036-1045.

[16] J. Hogan, J. A. Shaw, R. L. Lawrence, J. L. Lewicki, L. M. Dobeck and L. H. Spangler, "detection of leaking co gas with vegetation reflectances measured by a low-cost multispectral imager", IEEE Journal of Selected Topics in Applied Earth Observations and Remote Sensing, vol. 5, no. 3, (2012) June, pp. 699-706.

[17] “Atmel Microcontroller User Manual”, Motorola Products Corporation, 2325 Orchard Parkway, San Jose, CA 95131, http://www.atmel.com.

\section{Authors}

Md. Biplob Hossain, (S' 2014) is with department of Electrical and Electronic Engineering, Rajshahi University of Engineering and Technology (RUET), Rajshahi-6204, Bangladesh. Currently he is the chief course coordinator at Point Tech Bd., an engineering firm at Dhaka, Bangladesh (www.pointtechbd.in). His research interests are Electromagnetic Propagation Modeling, Simulation of Microwave Devices Using Time Domain Computational Methods, Graphene modeling and its applications, Image processing, Signal processing, Bio-medical and Bio-informatics engineering.

E-mail:biplobh.eee10@gmail.com, mohammad.hossain.biplob@gmail.com 
Saruar Jahan Shourov, (S' 2012) currently works as student of Electrical and Electronic Engineering, Rajshahi University of Engineering and Technology, Rajshahi-6204, Bangladesh, His research interests included power system analysis, automatic grid control system, high voltage, re-newable energy, Automatic Control system, Security and circuitry system.

E-mail: shourov101062@gmail.com

Md. Masud Rana, (S' 2014) currently serves as Assistant Professor of Electrical and Electronic Engineering Department, Rajshahi University of Engineering and Technology (RUET), Rajshahi-6204, Bangladesh. He completed his Ph. D in Electrical Engineering from University of Technology Sydney (UTS), Sydney, Australia in 2013. He received B. Sc in Electrical and Electronic Engineering from RUET, Bangladesh. He has currently membership of Institute of Electrical and Electronic Engineers (IEEE) and EEE Association of RUET. His research interests included Analytical and Computational Electromagnetics, Antenna theory and design, Electromagnetic Compatibility, Electromagnetic Propagation Modeling, Simulation of Microwave Devices Using Time Domain Computational Methods, Modeling Computational EM Fields Using FDTD Methods and Optical and Nano Structural devices Modeling Using Graphene.

Email: masud_0119e@yahoo.com, md.masud.rana.ruet@gmail.com

Website: http://www.ruet.ac.bd/teachers/EEE

Md. Shamim Anower, (S' 2012) currently works as Associate Professor of Electrical and Electronic Engineering Department, Rajshahi University of Engineering and Technology (RUET), Rajshahi-6204, Bangladesh. He received $\mathrm{Ph}$. D in Electrical Engineering from UNSW, Australia, M. Sc and B. Sc in Electrical and Electronic Engineering from RUET, Bangladesh. He is currently the member of Institute of Engineers Bangladesh (IEB), Institute of Electrical and Electronic Engineers (IEEE), EEE Association of RUET and Technical Committee of NCPNT. His research interests included Underwater Acoustic Signal Processing: Theory and Applications, Underwater Wireless Communication: Theory and Applications, Digital Signal Processing: Theory and Applications Advanced Power System Stability, Power Line Communication and Renewable Energy.

His Office Address is Administration Building 1 Room 137, Telephone: (+88) 0721750742 Ext 433 (Office), Fax: (+88) 0721 750356 (Office), Mobile: (+88) 01739816339

Email: md.shamimanower@yahoo.com,

Website: http://www.ruet.ac.bd/department/EEE 